\title{
Construção do Conhecimento Matemático: natureza, transmissão e gênese
}

\author{
Construction of Mathematical Knowledge: Nature, Transmission and \\ Genesis
}

\begin{abstract}
Resumo
A pesquisa visa a responder, com docentes de outros países, o mesmo problema de pesquisas anteriores realizadas no Brasil: que concepção epistemológica docente fundamenta o ensino, em particular, de Matemática? O objetivo específico é levantar concepções epistemológicas de docentes do exterior para saber se são congruentes com as encontradas no Brasil - predominantemente empiristas, amparadas às vezes por aprioristas e, raramente, construtivistas. O objetivo último é fornecer subsídios para transformar o ensino de Matemática. Analisam-se neste texto as respostas de 17 professores, de todos os graus de ensino, de três países sul-americanos, às três primeiras das 24 questões feitas aos docentes, mediante entrevistas. Foram encontradas basicamente as mesmas concepções epistemológicas do Brasil, sobre natureza, transmissibilidade e gênese do conhecimento matemático. Assemelham-se quanto à ausência de preocupação com a gênese do conhecimento matemático, à crença na transmissibilidade dos conceitos dessa ciência, à natureza desse conhecimento e à presença de concepções epistemológicas empiristas e aprioristas. Diferenciam-se, porém, quanto à presença, com certa intensidade, de concepções epistemológicas críticas (embora às vezes de forma inconsciente), à repercussão destas no ensino e nas concepções de aprendizagem dos conteúdos pertinentes e na insistente preocupação com a aplicação prática desses conhecimentos. A referência teórica que orienta a análise é a Epistemologia Genética de Jean Piaget, especialmente sua obra sobre abstração reflexionante, com foco na abstração pseudo-empírica. Criticam-se os mitos de que a Matemática está em tudo, de que os seres humanos nascem matemáticos e de que, enquanto matemáticos, são produtos da pressão social exercida pelo ensino escolar. Critica-se, igualmente, a baixa valorização da ação do sujeito na construção desse conhecimento.
\end{abstract}

Palavras-chave: Construção do Conhecimento Matemático. Epistemologia do Professor de Matemática. Transmissão do Conhecimento Matemático. Gênese dos Conhecimentos Matemáticos.

\begin{abstract}
This research aims to respond, with scholars from other countries, to the same problem as earlier studies developed in Brazil: which epistemological teaching conception underlies teaching, particularly in Mathematics? The specific objective is to survey epistemological conceptions of foreign teachers to know whether they are in line with those found in Brazil - which are predominantly empiricist, sometimes supported by aprioristic conceptions, and rarely constructivist. The final objective is to provide background to transform Mathematics teaching. Seventeen teachers from three South American countries were interviewed, using a 24-question script. This text presents their answers to the first three questions. Basically, the same epistemological conceptions found in Brazil were identified, considering the nature, transmission, and genesis of mathematical knowledge. They are similar in terms of the lack of concern with the genesis of mathematical knowledge, the belief in the transmission of this science's concepts, the nature of this knowledge and the presence of empiricist and aprioristic epistemological conceptions.
\end{abstract}

\footnotetext{
* Doutor em Psicologia Escolar e do Desenvolvimento Humano (USP). Professor Titular, aposentado, atuando como Docente Convidado (UFRGS), Porto Alegre, RS, Brasil. Endereço para correspondência: Rua Comendador Rodolfo Gomes, 403/104, Bairro Menino Deus, Porto Alegre, RS, Brasil, CEP: 90.150-101. E-mail: fbeckerufrgs@gmail.com.
} 
Nevertheless, they differ regarding the somewhat intense presence of epistemological conceptions that are critical (although sometimes unconsciously) towards their repercussions in teaching, in the learning conceptions of the pertinent contents, and in the insistent concern with the practical application of that knowledge. The theoretical framework that guides the analysis is Jean Piaget's Genetic Epistemology, especially his work on reflective abstraction, focused on pseudo-empirical abstraction. The myths criticized that Mathematics is present in everything; that human beings are born mathematicians and that, as such, they are products of the social pressure school education exerts. Similarly, the low valuation of the subject's action in the construction of that knowledge is criticized.

Keywords: Construction of Mathematical Knowledge; Epistemology of the Mathematics Teacher; Mathematical Knowledge Transmission; Mathematical Knowledge Genesis

\section{Introdução}

Esta pesquisa pretende continuar as pesquisas anteriores da Epistemologia do professor; o cotidiano da escola (BECKER, 2018) e da Epistemologia do professor de matemática (BECKER, 2012b), mas em âmbito internacional; num primeiro momento, em países sulamericanos, vizinhos do Brasil: Uruguai, Chile e Peru. A intenção é saber se os problemas epistemológicos que tanto comprometem o ensino de Matemática brasileiro são encontrados também na docência desses países. As concepções epistemológicas, empiristas ou aprioristas, negam o desenvolvimento cognitivo, à medida que concebem a origem da capacidade cognitiva humana como resultante da pressão do meio sobre uma tábula rasa ou como determinada pelo genoma, negando a influência da experiência, especialmente no sentido piagetiano de experiência lógico-matemática ou abstração reflexionante, e, como tais, determinam a concepção de aprendizagem da docência e, por consequência, seu ensino. Em segundo lugar, saber se esses problemas comprometem o ensino de Matemática tal como acontece no Brasil.

Foram entrevistados 17 professores de Matemática a quem foram dirigidas 24 questões, sendo oito professores universitários e nove de Educação Básica. Cinco uruguaios, quatro chilenos e oito peruanos. Quase todos eles lecionando em instituições públicas, tanto de Educação Básica, seja em zona agrícola ou periferia urbana de grande pobreza, seja de classe média, quanto de ensino universitário, público ou privado. Comparecem também docentes de instituições básicas e universitárias de elite. A idade dos docentes varia de 25 a 68 anos. Lecionam disciplinas como Cálculo, Equações diferenciais, Geometria, Aritmética, Álgebra, Análise, Tabuada.

A seleção dos 17 professores obedeceu a um critério básico: que os diferentes níveis de ensino de Matemática estivessem representados. Apenas num dos três países restringiu-se, por motivos que escaparam ao pesquisador, ao ensino universitário e de pós-graduação. Todos os docentes aceitaram o convite para serem entrevistados - entrevistas individuais - e receberam, 
previamente, explicações a respeito da finalidade das mesmas e da garantia do anonimato. As entrevistas, realizadas entre 2011 e 2016, duraram de 45 minutos à uma hora e quinze minutos e foram gravadas em áudio. A transcrição foi feita por bolsistas de iniciação científica com domínio do espanhol. Observações de sala de aula - uma aula de cada docente entrevistado não serão incluídas nesta análise, pois serão objeto de análise à parte.

Trata-se de pesquisa qualitativa com metodologia de análise de conteúdo repensada com elementos do método clínico piagetiano, com o objetivo de identificar as noções presentes nas respostas dos docentes. A leitura exaustiva das entrevistas permitiu eleger frases dos entrevistados à medida que levantavam, de forma instigante, problemas epistemológicos comuns aos docentes e no horizonte da proposta da pesquisa: basicamente, saber se o docente professa epistemologia empirista, apriorista ou concebe a capacidade cognitiva como resultante de construções do sujeito. O objetivo último da pesquisa é fornecer subsídios para transformar o ensino de Matemática, respondendo à pergunta: como pode um professor melhorar seu ensino professando concepções epistemológicas que remontam ao senso comum - empiristas ou aprioristas? As referidas frases levantam, além de problemas epistemológicos, problemas referentes à concepção de desenvolvimento cognitivo, de aprendizagem e, por consequência, de ensino; numa palavra, problemas de epistemologia genética e problemas pedagógicos.

A referência teórica básica para a análise das falas dos professores é a abstração reflexionante (PIAGET, 1995), especialmente a abstração pseudo-empírica, da epistemologia genética piagetiana. Justifica-se essa opção porque é Piaget quem nos traz com clareza a ideia de que o conhecimento matemático é uma construção humana, acessível a todos os humanos, por um processo que começa com as ações que são, progressivamente, interiorizadas em forma de operações. A escola não trabalha com essa ideia, na medida em que atribui, pelas concepções epistemológicas de seus docentes, a origem desse conhecimento a causas estranhas à ação do sujeito. Piaget (1995) explica essa gênese pelo processo de abstração reflexionante que concebe o sujeito humano como construtor dessa capacidade cognitiva, ou como "arquiteto de sua própria prática cognoscitiva" (FREIRE, 1997, p. 140). Justifica-se também essa escolha na medida em que a abstração reflexionante traz implícita uma teoria do desenvolvimento cognitivo e funda uma teoria de aprendizagem (PIAGET, 1975c; 1974) com ampla repercussão pedagógica e didática.

Embora quase não citado, Paulo Freire marca presença considerável nesta análise, especialmente pela obra Pedagogia da autonomia (1997).

Por meio da abstração empírica (PIAGET, 1995; BECKER, 2014; 2017), o sujeito retira qualidades dos objetos ou das ações enquanto observáveis; qualidades que pertencem aos 
objetos ou às ações e que estão neles antes da ação do sujeito sobre eles. Essas abstrações serão, no desenrolar do desenvolvimento cognitivo, cada vez mais possibilitadas e controladas pelas abstrações reflexionantes.

Por meio da abstração reflexionante, o sujeito, ao contrário do que ocorre na abstração empírica, retira qualidades das coordenações de suas ações (coordenações endógenas, portanto não observáveis). Essa abstração tem dois desdobramentos: a pseudo-empírica e a refletida. Pela abstração pseudo-empírica, o sujeito retira dos objetos qualidades que não pertencem a eles, mas que o sujeito atribuiu a eles ou colocou neles. Se eu nomear como "dois" a segunda peça, ao enumerar as peças da primeira fileira do ábaco, o "dois" não é uma qualidade da conta, é uma qualidade de quem enumera, uma qualidade de suas ações, ou de suas coordenações de ações; de tal modo que se pode começar de trás para a frente e, então, a peça “dois" será a penúltima peça dessa fileira. $\mathrm{O}$ dois foi colocado, tanto numa quanto noutra peça da primeira fila, pelo sujeito que as enumera; o número dois não pertence àquelas peças, pertence ao sujeito. Parece que o sujeito faz uma abstração empírica; na verdade, ele faz uma abstração pseudoempírica, isto é, falsamente empírica, pois ele tira de uma e de outra peça o dois que ele colocou lá e que não pertence às peças; faz, portanto, uma abstração reflexionante. É por abstração reflexionante que se consegue construir conhecimentos universais e necessários - como os conhecimentos matemáticos.

Todo o conhecimento matemático é criação e invenção do sujeito humano. Não é qualidade que pertence aos objetos por mais que se adeque aos objetos; e ele se adequa aos objetos porque o sujeito o construiu agindo sobre eles (PIAGET, 1973a). O conhecimento matemático compõe-se de qualidades das coordenações das ações do sujeito, retiradas dos objetos por abstração pseudo-empírica e logicamente organizadas. As qualidades da noção de número, como maior que/menor que, próprias das relações, intrínsecas aos números, não pertencem aos objetos; são retiradas das ações do sujeito, ações exercidas sobre os objetos. As qualidades todo e partes, próprias das classes, intrínsecas à noção de número, não estão nos objetos; são qualidades das coordenações das ações do sujeito. Por isso, afirmamos que a Matemática não está no mundo, na natureza, no universo, como afirmam vários entrevistados, tanto na atual, quanto nas pesquisas anteriores (BECKER, 2018, 2012b); ela está no cérebro ou na mente do sujeito. Embora o sujeito só possa fazer Matemática agindo sobre as coisas, ele não extrai a Matemática das coisas (do mundo exógeno); ele a constrói usando como matéria prima as coordenações de suas ações (do mundo endógeno) - ações originariamente efetuadas sobre as coisas (como acontece no período sensório motor).

É nesse sentido que criticamos o belo trabalho de Keith J. Devlin (2009), O instinto 
matemático: por que você é um gênio da matemática [assim como lagostas, pássaros, gatos e cachorros]? Esse matemático acredita que a Matemática está nas coisas e que os organismos não apenas humanos - sabem detectá-la no mundo, mesmo não tendo consciência disso; seus comportamentos mostram que sabem Matemática, mas não sabem que sabem. Assim, ele acredita que o cão, ao correr ao longo do lago antes de entrar na água, mostra compreender na prática, pelo seu comportamento de pegar a bola jogada no lago em direção oblíqua à sua margem, cálculo diferencial e integral. Acredita, também, que a formiga do deserto da Tunísia mostra, ao perfazer o longo trajeto de retorno, em linha quase reta, à sua toca, após ziguezaguear em busca de alimento, que sabe Matemática. Para não falar das admiráveis capacidades de orientação espacial de abelhas, morcegos, aves de arribação, gavião-peregrino.

Como se pode explicar essas capacidades de orientação espacial de mamíferos, insetos, aves? O universo tem certas leis de organização. Os organismos aprendem, com suas possibilidades instintivas e sua atividade perceptiva, a obedecer a essas leis - sem obviamente formulá-las e entendê-las. Eles agem sobre as coisas e logo aprendem que podem fazer certas coisas e outras não. Eles podem correr, nadar ou voar em certa velocidade, mas não além disso. Os animais de Devlin (2009) podem, com suas capacidades, alimentar-se de frutos, microrganismos, restos de organismos mortos, sempre dentro de certos limites. Mas eles não são capazes de se apropriar dessas suas capacidades e, com elas, constituir saberes diferenciados; não sabem, por exemplo, como construir um veículo para aumentar sua velocidade, uma geladeira para conservar alimento para o amanhã.

Expondo o processo de abstração pseudo-empírica, Piaget (1995) mostra-nos o caminho da construção das capacidades de quantificar, de enumerar e, na extensão delas, de conhecimento matemático. O sujeito, depois de longo exercício de abstração empírica, passa a retirar, com o auxílio da função simbólica (PIAGET, 1978b), qualidades das coordenações das ações, por abstração reflexionante. Mais ainda, passa a retirar qualidades dos objetos que não são próprias dos objetos, mas das coordenações de suas ações, qualidades que o sujeito colocou nos objetos. Reside ali a fonte do conhecimento matemático. O sujeito retira dos objetos qualidades suas, das coordenações de suas ações, que ele atribuiu aos objetos e, com elas, constrói novidades. A Matemática é, pois, uma construção humana, exclusivamente humana. Com ela o sujeito pode aproximar-se da estrutura íntima do mundo, da natureza, das sociedades humanas, do micro e do macrocosmo e, também, dos instintos dos animais não humanos, desde os grandes mamíferos até os insetos, aves, crustáceos, inclusive de plantas, como o girassol e as coníferas. Com ela o sujeito humano pode explicitar a maravilhosa harmonia e a beleza profunda de todas essas realidades. Pode matematizar o mundo. 
Quando o sujeito toma consciência de uma abstração reflexionante, incluindo a pseudoempírica, ele a transforma em abstração refletida. A construção de um conceito, de qualquer conceito, só se finaliza mediante abstrações refletidas. Inclusive, todos os conceitos matemáticos. Não observamos mamíferos não humanos fazerem isso por mais complexos e fascinantes que sejam seus comportamentos e suas capacidades perceptivas.

No início da entrevista, composta de 24 questões, fizemos três perguntas sobre (a) concepção de conhecimento matemático, (b) transmissibilidade do conhecimento matemático e (c) formação ou gênese desse conhecimento por níveis de progressiva complexidade. O texto analisa as respostas a essas três questões de 17 professores de matemática, de todos os graus de ensino, de três países sul-americanos (Uruguai, Chile e Peru); textos posteriores analisarão as respostas às demais questões. Iniciamos com as respostas à primeira pergunta.

\section{Natureza do conhecimento matemático}

\section{1 "A primeira coisa que penso é que não sei". "Não entendo a pergunta"}

Para situar os docentes quanto ao nível de ensino, usaremos a organização brasileira: Fundamental, Médio e Superior ou universitário. Atribuímos um número, de um a 17, a cada professor (P) (sem revelar o critério de organização da lista). Ao citá-lo, indicaremos esse número precedido de $\mathrm{P}$, entre parênteses. Exemplo: (P7; P12).

Pergunta-se aos docentes: “O que é o conhecimento matemático?”. O professor universitário (P3) começa a responder dizendo: "Quando penso na pergunta, o primeiro que penso é que não sei. Não sei o que é conhecimento matemático, mas, para mim, é conhecer certos resultados e ver como se aplicam”. O também professor universitário (P6) responde, não sem antes repetir a pergunta: “O que é?", dando a entender que a pergunta é inusitada. "O que é?", repete o entrevistador. "Não sei. Não sei defini-lo. Poderia dizer, isto é conhecimento matemático e isto não”. Outro professor universitário (P4) afirma: “É uma [pergunta] muito difícil. Não sei, é um conhecimento bastante formalizado e que tem uma sustentação lógica importante e, na realidade, sua origem vem de motivação muito prática como geometria, depois, mais tarde, a física”. O professor de sétimo e oitavo anos e de Ensino Médio (P10), depois de dizer que o ensino deve tornar a Matemática "tangível” para os alunos, para que “possam ver”, ao ser instado a responder à pergunta, diz: "Não entendo a pergunta".

Pode-se afirmar, com menor ou maior ênfase, que todos os 17 professores se sentiram desconfortáveis perante a pergunta “O que é o conhecimento matemático?”. A impressão quase 
unânime é a de que nunca pensaram nisso. A resposta à pergunta nada tem de fácil ou corriqueira. Entretanto, se um docente trabalha toda sua vida profissional com o conhecimento matemático, o mínimo que se pode esperar dele, ou que ele poderia ter exigido de seus formadores, é o conhecimento da natureza da matéria prima de seu trabalho, o conhecimento matemático. Não faz sentido trabalhar durante décadas com algo que não se sabe o que é, sua origem, sua natureza, seu significado; se pode ser transmitido ou se deve ser construído; ou como se relacionam construção e transmissão. Afinal, o que significa matematizar? Sua utilidade, ao contrário, são todos unânimes em reconhecê-la e com frequência insistem nela. $\mathrm{O}$ que os docentes mostram saber bem é apenas a mecânica do cálculo e sua aplicabilidade.

A busca pela gênese do conhecimento matemático leva-nos a duas origens combinadas: a filogenética e a ontogenética, a individual e a histórica; ou, como prefere Piaget, a psicogenética e a histórico-crítica. Quando e como surgem as primeiras respostas matemáticas aos problemas vividos por um indivíduo? Como evoluem tais respostas? Quando surgiram, na história humana, as primeiras respostas matemáticas aos problemas enfrentados por grupos humanos? Como evoluíram essas respostas?

As respostas dos entrevistados denotam que tais questões não fizeram parte de sua formação, ou fizeram de forma muito tênue. Nas respostas à primeira pergunta, apenas um docente (P6) fez menção passageira à primeira das duas origens. Diz ele: “[...] é o que sai nos trabalhos de investigação. O conhecimento matemático é isso acumulado ao conhecimento que já existe. É como uma pirâmide: começa com Pitágoras e se vai expandindo no tempo. Todo o trabalho de conhecimento, para mim, é acumulado”.

Vejamos outros aspectos das respostas dos sujeitos à mesma pergunta.

\section{2 "Professora, por que devo saber isto, se, ao final, não vou usar [aplicar] porque vou vender batatas?"}

Deve haver razão para que a pergunta pela natureza do conhecimento matemático receba amplamente como resposta, da parte dos docentes, a aplicabilidade desse conhecimento. Diz uma docente universitária (P12) de primeiro semestre: "Conhecimento matemático é conseguir que a pessoa seja capaz de realizar operações matemáticas e, de acordo com o contexto onde está, possa dar solução aos problemas [...]”" de Matemática. Diz a professora de oitavo ano do ensino fundamental (P16): “É saber aplicar a matemática na vida real, e o que mais custa, eu creio, como professora, é saber como motivar as crianças para que elas entendam o conceito em si de matemática, e poder levá-lo à prática, porque algumas dizem: 'Professora, por que 
devo saber isto, se, ao final, não vou usar [esse conhecimento] porque vou vender batatas ${ }^{1}$ ?". Este excerto da entrevista com essa professora mostra bem a dificuldade de pensar o conhecimento matemático na sua origem, na sua natureza, na sua gênese; numa palavra, de que conhecimento se está tratando. Diz ela (P16):

Tem que se ir à realidade das crianças e tratar com isto de saber os conceitos.

"O que é mesmo o conhecimento matemático?", pergunta o entrevistador.

O conhecimento matemático é um conhecimento de aplicação, de utilizar...

"E antes de ser aplicação? [...] Tu sabes operar, fazer aritmética, somar, multiplicar, dividir e, então, tu podes aplicar. Mas, sem aplicar, o que ele é? Como é que tu te representas o conhecimento matemático?'”

Como que eu tenho o conhecimento matemático para aplicá-lo ao ensino?

"Sim, mas antes de aplicar, o que tu pensas que é o conhecimento matemático?"

Aquilo que tenho que saber antes de aplicar? Bom, obviamente, as operações básicas, saber os algoritmos que existem porque há diferentes formas de ensinar uma mesma operação. Então, saber como poder ensiná-los de diferentes formas. E eu creio que o que mais falta aqui [neste país], é saber com qual método ensinar a matemática, com qual metodologia [de ensino].

Parece que a pergunta soa completamente inusitada à professora. Todo conhecimento matemático é produto de generalizações; todo aprendiz tem que fazer para si o que os matemáticos já fizeram. Esse conhecimento extrapola sempre o âmbito para o qual ele foi construído. Ele foi construído para resolver um problema e, ao ser construído, ele passa a resolver uma infinidade de problemas; ele se generalizou. Sua natureza não se define ou se esgota em sua aplicação. Para a professora, isso soa estranho de tal modo que ela confunde natureza ou origem do conhecimento matemático com pré-requisitos, no sentido dos currículos acadêmicos ou escolares. Quando o primeiro egípcio deu uma resposta matemática aos problemas enfrentados pela agricultura, devidos às enchentes do rio Nilo, ele inventou um conhecimento que extrapolou os problemas locais; criou um conhecimento universal que não se aplicará apenas aos problemas enfrentados pelos cidadãos egípcios afetados pelas enchentes do Nilo. Inventou um conhecimento que já atravessou milênios e fronteiras. Por isso, o conhecimento matemático não pode ser reduzido a conhecimento de aplicação; ele precede sua aplicação, senão cronologicamente, ontologicamente. Ele nasce num contexto de aplicação, mas, antes mesmo da aplicação, ele acontece como coordenações de ações do sujeito humano; como construção por abstração reflexionante, de tipo pseudo-empírica e refletida, a partir dessas coordenações. A matemática expressa formas gerais de organização das ações do sujeito humano - o único mamífero que é capaz de matematizar.

Embora a pergunta visasse à concepção epistemológica dos docentes, reiteradamente apareciam respostas abordando o ensino de Matemática. A professora de Ensino Fundamental

\footnotetext{
1 "Vender batatas", aqui, não é uma metáfora. Aquela região chilena é conhecida pelo cultivo da batata inglesa, um dos principais produtos agrícolas da região de Temuco.
} 
(P17) afirma que o conhecimento matemático "É parte da educação que ajuda a formar o pensamento lógico na criança. Ensina-lhe a ser precisa, ter método, ser detalhista, encontrar importância nos detalhes. Todos sabem que a matemática ajuda em todos os âmbitos da vida, sobretudo na resolução dos problemas que estão todos os dias em qualquer aspecto da vida". Novamente, a origem da matemática não lhe preocupa, interessa-lhe o destino educativo dessa ciência e sua instrumentalidade. A professora universitária (P1) vai na mesma direção:

Penso que o conhecimento matemático é saber aplicar, pensar lógico [...]. Não basta saber, por exemplo, como se comporta uma determinada função, tem que saber também aplicá-la. Então, esse conhecimento também é aplicação.

"De onde vem o conhecimento que tu estás aplicando?"

Primeiro, se aprendem certos conceitos, mas, para poder realmente internalizá-los, tem que exercitar muitíssimo. Há o momento de exercitar para fazer as conexões na cabeça e ver realmente do que se está falando.

"Tu referiste a lógica, o conhecimento matemático é sempre lógico?"

Não lhe entendo.

"O conhecimento matemático implica lógica?"

Sim, eu creio que implica a lógica. Eu creio que por trás do conhecimento matemático sempre há uma estrutura lógica. Por exemplo, saber demonstrar algo, saber passar de um passo a outro. Saber o que é correto, ou incorreto. Então, esse conhecimento tem lógica por trás.

"De onde o indivíduo tirou essa estrutura lógica? Ou ele sempre a teve?"

Ah, esta é uma boa pergunta! De onde [ele] a tem? Há alguns que têm uma intuição matemática, mas se não é ensinado, sem uma certa estrutura, é difícil que vá armar.

Inconscientemente, parece, os docentes fogem da pergunta da gênese, da origem do conhecimento ou pensamento matemático. Deixam a impressão de que nunca pensaram ou foram instados a pensar a respeito. Quando se descobre que a gênese do conhecimento matemático remonta à gênese de todo conhecimento ou de toda capacidade cognitiva, remonta à diferenciação dos aspectos qualitativos e quantitativos de todo conhecimento, à evolução do conhecimento em todos os sujeitos humanos e que esse processo precisa ser retomado para que a aprendizagem logre êxito, então sua importância assume um significado considerável. Mas essa gênese aparece, nas respostas dos docentes, apenas por vislumbre; aparece como lógica já constituída que se pode aplicar a tudo; não como processo formador. Para eles, sua origem está no ensino; na aprendizagem provocada pelo ensino e nas repetições que julgam necessárias para essa aprendizagem. Antes disso, há um vazio conceitual e processual; um vazio epistemológico. Ensinam-se conceitos para que os sujeitos os aprendam, isto é, “[...] para poder realmente internalizá ${ }^{1}$-los - continua essa professora universitária $(\mathrm{P} 1)$-, tem que exercitar muitíssimo

\footnotetext{
${ }^{1}$ Piaget fala em interiorização das ações como coordenações de ações; ações interiorizadas constituem operações. Como tudo na psicogênese cognitiva começa, segundo ele, pela assimilação, e o sujeito assimila mediante esquemas previamente construídos, o conhecimento nunca é simples resultado da pressão do meio, mas da construção efetuada pelas ações do sujeito. A função do meio é desequilibrar e ele só afeta o sujeito pelas assimilações do próprio sujeito. Vygotski é quem insiste em internalização (ROSSI; ROSSI, 2012). Ele acredita
} 
[para] fazer as conexões na cabeça e ver realmente do que se está falando". O modelo empirista salta aos olhos: ensinar conceitos e, em seguida, exercitar muito para internalizá-los. Um conceito não é compreendido pelos docentes como resultado de uma construção (mundo endógeno), como resposta do sujeito a desafios propostos pelo ensino, pela realidade física ou pelo entorno social, pela interiorização das ações; mas, como internalização de algo ensinado (mundo exógeno), realizada pelo exercício. Ainda não se deram conta de que conceitos não se ensinam, constroem-se. Um ensino que não pode contar com as construções do sujeito da aprendizagem, invariavelmente, redundará em fracasso.

Pode-se dizer que a capacidade de matematizar stricto sensu - conseguir operar somas e subtrações como operações reversíveis - surge na criança quando ela constrói a noção de número como extensão da noção de quantidade; Piaget situa esse evento pelos 7-8 anos de idade, quando a criança consegue sintetizar as classes e as relações lógicas, previamente construídas, reunindo-as em uma totalidade operatória. A criança dessa idade já construiu um aparato lógico de enorme complexidade, é só examinar suas brincadeiras, suas imitações, seus raciocínios "transdutivos" e sua fala (PIAGET, 1978b); e também sua capacidade de somar objetos e enumerar. Piaget et al (1968) refere a construção da noção de número como ponto de chegada de um longo processo de construção da reversibilidade que se iniciou já no sensóriomotor com a construção do objeto permanente e do "grupo de deslocamentos"; por exemplo, o bebê de 10-12 meses de idade organiza deslocamentos, de objetos e de seu corpo, coordenandoos.

Ferreira (2012) analisa modelos de estudiosos da formação do número, como de Von Glasersfeld e colaboradores e K. Fuson. Os primeiros afirmam que a contagem das unidades numéricas se dá por atividade complexa na qual exercem importante papel fatores perceptivos e motores; o início dessa atividade remonta, pois, às ações sensório-motoras, passa pelas coleções figurais, por unidades motoras, chegando até unidades verbais e abstratas (formais). Já K. Fuson (FERREIRA, 2012) afirma que esse processo se estende dos três anos e meio aos oitos anos de idade observando-se o uso de denominações verbais, na seguinte sequência: contexto cardinal, contexto ordinal, contexto de medida. E afirma a existência de cinco níveis de desenvolvimento na elaboração da sequência de numerais (FERREIRA, 2012). Diz Ferreira (2012, p. 203):

Em relação ao processo de aquisição dos numerais bem como das diferenças qualitativas nas representações mentais que as crianças vão elaborando sobre os

que um fenômeno psicológico é antes de tudo social; que a formação do sujeito consiste em internalizar fenômenos sociais, tais como a linguagem. Essa é uma discordância considerável, de fundamentação epistemológica, entre esses dois autores. Assume-se, no texto, a posição piagetiana. 
mesmos [...], os resultados mostraram que o processo de integração entre a sequência dos numerais, a contagem e o seu significado é bastante complexo.

Szeminska (PIAGET; SZEMINSKA, 1995), investigando “Abstrações, diferenciações e integrações no emprego de operações aritméticas elementares", com crianças de pouco menos de cinco anos de idade até pouco mais de treze, afirma: "Fica-se surpreso pelo fato de que seja preciso atingir este nível de idade - 12 a 13 anos - para raciocínios tão simples; mas há casos em que somente a abstração permite a simplicidade dedutiva" (PIAGET; SZEMINSKA, 1995, p. 26). Os resultados obtidos "mostram, à exaustão, as dificuldades que o sujeito deve vencer para chegar à constituição de tais totalidades coerentes" (PIAGET; SZEMINSKA, 1995, p. 28). O pensamento matemático surge como diferenciação quantitativa do aparato lógico qualitativo construído pela criança; é tributário desse aparato, não apenas na gênese, mas em todo seu desenvolvimento na vida dos indivíduos.

Essa capacidade não deve ser confundida com a capacidade mnemônica de crianças pequenas que decoram a sequência dos nomes dos números naturais.

\section{3 "Não podes escapar da matemática; a matemática está presente em tudo". "A matemática está na mente, mas as pessoas estão na vida"}

\footnotetext{
Uma ideia interessante aparece com certa recorrência na fala de entrevistados, a de que não se pode escapar do conhecimento matemático. Não adianta trocar de curso universitário para fugir da matemática, dizer que não gosta dela etc., pois ela faz parte da vida, do cotidiano. Diz a professora universitária (P13): Bom, a matemática, como todos sabemos, está presente em tudo. Nada lhe escapa. Por mais que se diga 'Vou para o Direito', não te escapas da matemática. [...]. Para mim, o conhecimento matemático é o porquê das coisas [...].

"A matemática está nas coisas ou está na mente do matemático?"

Não entendi bem.

"A matemática está na mente do matemático ou nas coisas, no mundo, no Universo?"

A matemática está no Universo; está nas pessoas... [...]

"Está na mente ou está nas estrelas, nas árvores, nas pedras, no mar?"

Em tudo, para mim, em tudo.
}

O professor universitário (P2) de Matemática pura diz: “A resposta é, eu não sei”. Em seguida - repercutindo as afirmações da docente anterior - afirma que " $O$ conhecimento matemático é algo que está em todas as pessoas". E acrescenta que "As crianças, desde muito pequenas, já adquirem conhecimento matemático”. Para ele, a Matemática é uma questão da natureza e todo mundo tem conhecimento matemático. Para ilustrar essa estranha concepção, ele (P2) explica:

O exemplo que eu gosto de dar aos meus alunos é a de um círculo ou uma circunferência. Todo mundo sabe o que é isso, qualquer pessoa mesmo que não seja matemática, que nunca tenha estudado, entende o que é isso [um círculo ou uma circunferência]. Mas isso é um conceito 
matemático abstrato [formal]. Ninguém ensinou e ninguém viu. Tu nunca viste um círculo! Não dá para ver, não existe. Se você olhar com uma lupa, uma coisa que pareça um círculo [vai notar que] não é um círculo perfeito; [isso] não existe na natureza. A pessoa tem isso. [...]. É um conceito completamente abstrato [formal].

O professor confunde intuição perceptiva com conceito. Uma criança pode reconhecer perceptivamente um círculo ou uma circunferência. Mas levará muitos anos para construir os conceitos de círculo e de circunferência. Noções de círculo ou de circunferência não são inatas; a criança as constrói por intuição espacial. Uma criança de um ano sequer tem essa noção; que dirá um bebê de quatro meses. Para chegar ao conceito de que fala esse docente são necessários muitos anos de evolução cognitiva individual; de abstração reflexionante, em especial pseudoempírica, com inumeráveis abstrações empíricas, para chegar aos respectivos conceitos entendidos como totalidades operatórias (interiorização das ações como coordenações), plenamente reversíveis. Somente quando dispuser de operações formais já consolidadas a criança, já adolescente, conseguirá construir esses conceitos. Sem ensino é difícil imaginar como chegar a eles; mas o ensino não é suficiente para adquirir esses conceitos; urge que o sujeito os construa. E muitos humanos jamais o conseguirão por força da exclusão social (FREIRE, 1979) que impede a inclusão educacional; não só inclusão escolar, mas inclusão escolar qualificada.

Esse docente (P2) afirma a existência, para o círculo ou a circunferência, de um a priori, assim como Kant (1997) afirmava que espaço e tempo são formas a priori da sensibilidade ou percepção; só que, surpreendentemente, o entrevistado afirma-o como "conceito abstrato [formal]" que todos têm. "A pessoa tem isso", diz ele. Um "conceito completamente abstrato" que “qualquer pessoa mesmo que não seja matemática, que nunca tenha estudado”, tem isso. Todo mundo tem, mesmo que "Ninguém ensinou e ninguém viu" (P2). O docente afirma o mesmo para o conceito de número e para as qualidades em comum de diversos conjuntos. Com certeza, ele não estranharia a tese defendida por Devlin (2009), acima abordada. Ele sintoniza, pelo menos em parte, com esse autor, ao afirmar que todos têm conceitos matemáticos completamente abstratos, inclusive crianças e analfabetos. Há um abismo cognitivo entre reconhecer a figura de uma circunferência e conceituar uma circunferência; isso escapa a esse professor de Matemática pura, como escapa a Devlin (2009), que atribui conhecimento matemático instintivo aos animais que estudou. Entretanto, eles sequer são capazes de reconhecer a representação gráfica de uma circunferência; muito menos o conceito.

Se a Matemática está presente em tudo, quem a colocou lá? Ou está lá depois que o sujeito humano a construiu para compreender o entorno, a vida, a sociedade, o universo, por um demorado processo de construção "sem fim e, sobretudo, sem começo absoluto?" (PIAGET, 
1995, p. 277; BECKER, 2012a).

Frente a essa complexidade, a professora universitária (P5) se pergunta: "O que devo ensinar? Que conhecimento devo transmitir?”. A propósito, tratar-se-á, em seguida, da transmissão de conhecimento matemático. O que pensam os docentes a respeito? Como respondem à pergunta: “O conhecimento matemático pode ser transmitido?”. Vejamos como se configuram as respostas dos docentes a essa pergunta.

\section{Transmissibilidade do conhecimento matemático}

É inquestionável a função social da transmissão de conhecimentos, em especial do conhecimento matemático. Piaget (1972) arrola a transmissão social, como a da escola, ao lado da maturação, da experiência - física e lógico-matemática - e da equilibração, como fator responsável pelo desenvolvimento cognitivo, mas não suficiente para explicar sua gênese. A explicação do desenvolvimento cognitivo resulta do conjunto desses quatro fatores, regulados os três primeiros pela equilibração. A questão não reside, pois, em admitir ou não a transmissão, mas em saber se ela funciona autonomamente ou na dependência de condições. Saber se basta a transmissão para surgirem capacidades cognitivas ou se ela é uma condição importante, mas que sozinha não explica o surgimento dessas capacidades; se seria necessária a intervenção de outros fatores. Predomina entre os docentes a crença de que a transmissão é condição suficiente de aprendizagem de conhecimentos matemáticos desde, entretanto, que o aluno faça exercícios; isso é, que internalize (ver nota de rodapé 2), pela repetição, os estímulos da docência. Acreditam que o ensino é suficiente para compreender; mas, para memorizar, serão necessários exercícios. A epistemologia empirista está na base dessa compreensão. Por outro lado, aparece a crença da transmissão genética desse conhecimento.

\section{1 "Acredito que [...] há uma transmissão genética. Que [...] assim como transmitimos a nossos filhos [...] a propensão ao câncer, igual há uma certa transmissão" de conhecimento}

O professor de Ensino Médio (P8) acredita que não há apenas transmissão social do conhecimento matemático, mas também genética. Está convicto que, de alguma forma, assim como se transmite aos filhos "os vírus, a propensão ao câncer, igual há uma certa transmissão" genética de conhecimento. Exemplifica sua hipótese com seus filhos que "vão pela área da matemática”. Ele admite que há um processo de transmissão social, de desenvolvimento, isomorfo ao genético. Não explica, porém, como se relacionam os dois. Apenas, que os 
conhecimentos matemáticos seriam "transmitidos de ambas as formas, pelo genético e pelo desenvolvimento". "Eu acredito, tenho a suspeita que a criança vem com as duas coisas. Ou seja, tem, de fato, um potencial que lhe permite o desenvolvimento de suas próprias capacidades e tem, também, a transmissão genética”. Continua ele (P8):

Pelo menos é o que eu tenho lido... Há alguns estudos que nos fariam supor que, pela facilidade que a criança tem de aprender, há algumas coisas, alguns conhecimentos que, parece, vêm incorporados em seu disco rígido desde pequena. E isso para mim parece que está em seu código genético.

Podemos afirmar que a quase totalidade dos docentes entrevistados não distingue hereditariedade geral de específica, na contramão de Piaget (1973a), que propõe que se herda a capacidade (geral) de construir estruturas (MONTANGERO; MAURICE-NAVILLE, 1998) ou capacidades cognitivas; não se herdam capacidades (específicas) como as estruturas matemáticas ou da linguagem. Segundo Piaget (1978a; 1973a; 1973b; 1995), elas são construídas na interação sujeito-meio. A capacidade de somar e subtrair, de forma reversível, quantidades quaisquer, é construída tardiamente. Essa construção é possibilitada por um demorado processo, que remonta à coordenação de esquemas sensório-motores, às coleções figurais (PIAGET, 1978b), à contagem das unidades numéricas; em resumo, por ações de classificação e de seriação lógicas de cuja síntese (PIAGET; SZEMINSKA, 1975b, p. 311) origina-se a noção de número. "Mais uma vez, [...], o número surge como a síntese da classe e da relação assimétrica, ou, o que vem a dar no mesmo, da relação simétrica (igualdade) e das diferenças (relações assimétricas)".

Esse modo de pensar de docentes funda-se numa epistemologia apriorista, biologicamente inatista; acreditam eles na herança genética das capacidades matemáticas. Fazem conviver essas duas concepções epistemológicas - o desenvolvimento das próprias capacidades e a transmissão genética - atribuindo a cada uma delas um papel. Compreendem que não há contradição entre elas.

Essa compreensão surpreendente da determinação genética do conhecimento matemático foi manifestada por alguns docentes; a maioria, entretanto, atém-se à postura empirista segundo a qual a transmissão social, especificamente pelo ensino, dos conhecimentos matemáticos, é condição suficiente de sua aprendizagem. Raramente aparece a hipótese da construção das capacidades matemáticas como condição da aprendizagem dos conteúdos matemáticos.

\subsection{Conhecimento matemático tem que ser construído}


Docentes afirmam que o conhecimento tem que ter sido construído, porque os conteúdos matemáticos são produtos da criação humana; por isso, têm que estar incluídos na sala de aula. Mas deve-se traduzi-los pedagogicamente para que o aluno ative sua mente, sua cognição. Para que ele assimile e reestruture seus sistemas mentais; só assim esses conteúdos se converterão em conhecimento. É significativa a resposta de um docente universitário (P2) de Matemática pura a esta pergunta: "Pensas que existem duas coisas: o conteúdo matemático e o conhecimento matemático?" Acompanhemos sua resposta:

Sim. Há obviamente [as] duas coisas. Você não pode explicar o que é um círculo para um cara que vem lá de Marte. Impossível explicar uma coisa que não dá para ver. Como ensinar o que é vermelho para um cego. O que é um círculo, você não pode transmitir esse conhecimento. Esta intuição que a pessoa tem. Mas eu posso dar uma fórmula para ele e dizer: 'Um círculo é $x$ ao quadrado mais y ao quadrado igual a 1 '. Isso é um círculo para um matemático que é burro e não tem o conceito, como o computador. Não tem jeito. A imaginação da pessoa, isso aî é difícil. Você pode incentivar, mas... (P2).

Outro docente (P14), também de Matemática pura, é ainda mais enfático. Diz ele (parafraseando sua fala para não a apresentar com muitos cortes, mas conservando ao máximo suas frases): Creio que não se pode transmitir conhecimento matemático. Podem-se transmitir estratégias de como se pensam as coisas para que o aluno também proceda assim. Há os que pensam que o conceito de número está enraizado no cérebro e que se pode falar através da árvore genealógica, tal como os mentores da gramática gerativa, entre os linguistas. Eles dizem que a gramática está impressa, de certo modo, no cérebro. A matemática seria, nesse sentido, um pouco igual à música. Não se pode transmitir conhecimento. O que se pode fazer é ajudar a delimitar, dar estratégias ao ser humano para que pense sobre o assunto, mas é sua própria mente que deve fazer conexões com a realidade do momento. Pergunta-se, então, se o aluno tem que adotar essas estratégias. Responde ele:

Não está obrigado. Um professor é somente um; existem muitos professores. O aluno tem que se valer de uma ou outra aula, uma conferência, livros; o aluno tem que agarrar tudo que está por ali, diferentes estratégias para solucionar um problema e pode ser que consiga elaborar sua maneira de fazê-lo. Eu não posso transmitir ao aluno conhecimento, não existe fórmula. Eu posso organizar, saber o quanto de conhecimento uma turma pode absorver em uma semana; o aluno pode usar anotações, livros, exercícios e outras coisas para fazer sua própria conexão com a realidade $(\mathrm{P} 14)$.

Não deixa de ser uma surpresa, agradável e rara, ouvir de professores, doutores em Matemática pura, a ideia de construção cujo corolário é a não transmissibilidade do conhecimento matemático; transmitem-se informações, conceitos não; estes são construídos. Sua oposição à ideia da gramática gerativa de Chomsky, de que "a gramática está impressa, de certo modo, no cérebro", é mais do que um avanço epistemológico; leva a um avanço pedagógico. A matemática não está impressa no cérebro do recém-nascido; ela é resultado de 
construções do sujeito. A clareza desse docente não deixa dúvidas: "O que se pode fazer é ajudar, delimitar, dar estratégias ao ser humano para que ele pense sobre o assunto, mas sua própria mente deve fazer conexões com a realidade do momento"; "o aluno pode usar anotações, livros, exercícios e outras coisas para fazer sua própria conexão com a realidade" (itálicos nossos), para construir seu conhecimento, sua capacidade cognitiva.

Pode-se responder às falas desses docentes dizendo que o ser humano nasce com a capacidade para construir conhecimento matemático (hereditariedade geral); não nasce com conhecimento matemático de qualquer tipo; não nasce com a noção e muito menos com o conceito de número, por exemplo. Nossa ignorância sobre os percalços da formação do número (PIAGET; SZEMINSKA, 1975b), das quantidades físicas (PIAGET; INHELDER, 1975a), das estruturas lógicas elementares (PIAGET; INHELDER, 1975c), das abstrações empírica e reflexionante, pseudo-empírica e refletida (PIAGET, 1995) que Piaget tão bem rastreou, nos leva a fantasiar que essas competências já se encontram no recém-nascido humano. Da mesma forma que o comum das pessoas, frente à performance surpreendente de uma criança de nove anos, ao interpretar uma música ou executar um instrumento musical com maestria, afirmam enfáticos: É talento. É um dom. Nasceu assim.

\section{Conhecimento novo}

\subsection{Primeiro, apresentamos mal a matemática; segundo, a fixamos mal nos alunos}

Os docentes responderam à pergunta: "Como se passa de um conhecimento matemático mais simples para um mais complexo?’. Procura-se saber, com essa pergunta, como eles explicam a produção de conhecimento matemático novo.

O professor de Educação Secundária (P8) afirma que, para se passar de um conhecimento mais simples para um mais complexo, deve-se começar perguntando à criança para saber o que ela já conhece. É sobre essa base que ele tenta construir o que se segue, na disciplina que leciona. Critica o ensino que se pratica na medida em que, segundo afirma, "primeiro que apresentamos mal a matemática, segundo, a fixamos mal” nos alunos. Critica igualmente os colegas da Educação Primária [Ensino Fundamental] porque não sabem distinguir o que é principal do que é secundário; atribuem, segundo ele, o mesmo peso e a mesma importância para todos os conteúdos. "Há coisas que são o tronco, sobre o qual se pode sustentar tudo”. Por isso, pensa, "não se fixam na criança as coisas adequadamente”.

Para o professor, deve-se partir do conhecimento dos alunos como base para construir o 
que vem depois; isso é, partir do conhecimento mais simples. O professor (P8) pensa que a Matemática deveria ser a matéria escolar mais fácil porque as propriedades "que servem para os [números] naturais servem para os inteiros, para os racionais. [...]. O único que tu terias que ir fazendo é ir pendurando uma pecinha a mais, outra pecinha a mais. Mas aí tu te bates com uma dificuldade [...]" da qual os professores parecem não se dar conta. Ao tratar das propriedades dos inteiros, não levam em conta o que eles têm em comum com os outros números. Por isso, ao tratar dos racionais, iniciam do ponto zero sem aproveitar o que trataram antes. "Aprender o mais simples é condição suficiente para aprender o mais complexo?" pergunta o entrevistador. Não é suficiente, responde ele. São várias coisas que entram em jogo. Uma é a afetividade. "Uma coisa tradicional é que os professores de matemática eram os mais odiados. Aqui (escola privada), isso já foi superado”.

O professor afirma que, especialmente nos primeiros anos, deve-se partir do simples para o complexo. "Porque muitas vezes cometemos o equívoco de começarmos pelo contrário, damos uma pergunta complexa e a criança se confunde. É importante, sim, começar pelo simples".

Embora pertinentes as críticas do professor aos procedimentos docentes, na disciplina de Matemática, o que nos interessa aqui é sua concepção epistemológica. Ele afirma que o ensino que se pratica primeiro apresenta mal a Matemática; segundo, "a fixamos mal” nos alunos; "não se fixam na criança as coisas adequadamente". O docente professa um empirismo primitivo segundo o qual a matemática é apresentada (como estímulo) mal aos alunos e fixada (exercícios, repetição) mal neles. Ele pensa que, se os estímulos, junto aos alunos, são mal trabalhados pela docência, como se poderá garantir respostas de qualidade? Provavelmente limitado por sua concepção epistemológica, o docente não explica em função de que se passa de um conhecimento mais simples a um mais complexo. Ele põe o ensino no lugar do processo de construção; pensa que o estudante não constrói conhecimento, é o professor que passa ao aluno o conhecimento mediante estímulos e, exigindo exercícios ou repetições, fixa no aluno esse conhecimento. Para o docente, o aluno é objeto do ensino, não sujeito da aprendizagem.

Há um procedimento trabalhoso, de intensa atividade, da parte do sujeito para transitar do simples ao complexo. A concepção empirista do professor escamoteia essa atividade do sujeito - do aluno - pondo em seu lugar a atividade do professor que "expõe" e "fixa" no aluno o conhecimento já elaborado. É por isso que ele afirma que se deve começar perguntando à criança o que ela já conhece (conteúdo); em vez de perguntar do que ela é capaz (estrutura, competência ou capacidade). Se o sujeito constrói competências ou estruturas, ele vai se tornando capaz de aprender conhecimentos cada vez mais complexos e em maior quantidade. 


\subsection{O aluno precisa encontrar relações, fazer a reflexão necessária}

Ao contrário do professor anterior, a professora de Ensino Médio (P11) afirma que a passagem de um conhecimento mais simples para um mais complexo se dá por relações e reflexões realizadas pelo aluno. "Pela minha experiência, me dei conta que os alunos têm que ir relacionando a[s] ideia[s], têm que ir refletindo sobre o que estão fazendo. Se fazem mecanicamente, não compreendem a realidade”. Não adianta dizer a eles que se somarmos números repetidos chegaremos a uma multiplicação. O professor pode dizer ao aluno, mas o aluno não o compreende. "Porque ainda não encontrou relações, não fez a reflexão necessária”. Porque não construiu as condições prévias.

A docente universitária (P15), que capacita professores de Ensino Fundamental, concorda e acrescenta: "os mais simples se adquirem na infância através de ações fisicas, de manipulação física que a criança faz”. O mais complexo vem “à medida que se vai assimilando, vai construindo relações lógicas, conceitos matemáticos que se transformam em conhecimentos; o aprendiz, o aluno vai desenvolvendo uma capacidade de abstração cada vez mais elevada, de maior profundidade e, então, [converte] a manipulação física em uma manipulação mental". Surge, então, a capacidade de "manipular objetos matemáticos".

Fica claro que esses docentes deslocaram do professor para o aluno o mérito da aprendizagem. Não é o trabalho do professor que apresenta e fixa nos alunos os conceitos matemáticos, mas a ação do aluno que os constrói - com a importante ajuda do professor. Das ações físicas da primeira infância, a criança vai tirando relações com as quais constrói novas relações, relações sobre relações, até chegar às "relações lógicas”, aos “conceitos matemáticos”. De nada adianta o professor informar os alunos sobre as elaborações matemáticas, que vêm desde Pitágoras, sem o trabalho reflexionante (Piaget, 1995) ou, como diz o docente, sem a "reflexão necessária do aluno".

\subsection{Compreender 0 antes é condição suficiente para o que vem depois?}

O professor universitário (P3) afirma que: “Começa-se com uma ideia simples e se vai elaborando-a, jogando com a ideia e se vai chegando a conhecimentos mais complexos". Mesmo assim, ele reclama: "Não sei se entendi bem a pergunta". "Como se passa da aritmética para a álgebra, desta para o cálculo diferencial e integral? Basta compreender uma para passar à outra? Ou tem que fazer alguma coisa a mais?". Ela responde: 
Não precisa [fazer algo a mais], mas há que compreendê-la, primeiro. É uma condição necessária, mas não suficiente. Você tem que aprender primeiro a manipular, ainda que não se entenda muito bem o porquê, como se faz no ensino elementar ou no secundário. Depois que começa a aprender a manipular, vai começar a entender (P3).

Já a professora das últimas séries do Ensino Fundamental (P17) insiste que "Tem que haver uma sequência. Sempre do mais simples ao mais complexo. Não posso partir do contrário, não posso partir do complexo”. Se as crianças vão aprender a dividir números decimais, elas têm que, antes, aprender a dividir os naturais. Pergunta-se, então, se basta aprender os números naturais para aprender os decimais. Ela diz que não e afirma "que há muitas outras coisas. Os números decimais também se multiplicam por potências de dez. Eles [os alunos] têm que dominar o que são potências de dez, têm que dominar as tabuadas, tem que dominar os algoritmos básicos”. Em Matemática, diz ela, "para aprender algo tem que ter conhecimento prévio; me centro neste aprendizado para me lançar a outro conhecimento superior. Sempre são passos que se vai dando”. Pergunta-se, então, se basta o conhecimento prévio para aprender o seguinte. Conhecimento prévio, diz ela, é uma parte, mas, para que a criança aprenda, "tem que ter uma boa metodologia, um bom ambiente de trabalho, professor que domine suas disciplinas". E o aluno, o que ele precisa para transitar para um conhecimento mais complexo? "Tem que estar motivado, ter disciplina, autodisciplina também, que os conhecimentos se reportem, estejam de acordo com a realidade dele e que ele possa entendêlo".

Esses docentes respondem à pergunta de caráter epistemológico com a didática da Matemática. Mesmo quando se aproximam de uma resposta epistemológica, reduzem sua resposta a expedientes didáticos. Afinal, em função do que se passa de um conhecimento menos complexo a um mais complexo? O que acontece com o sujeito quando logra passar da soma para a multiplicação, da subtração para a divisão, dos números reais para os decimais, da aritmética para a álgebra? As respostas dos 17 professores à pergunta sobre a gênese do conhecimento novo, da passagem do mais simples ao mais complexo, permaneceram no plano didático-pedagógico; mas, indiretamente, mostraram a predominância de concepções epistemológicas empiristas ou aprioristas.

\section{5 À guisa de conclusão}

Pode-se dizer que a criança pequena, até os 7 a 8 anos em média, tem noção de “quotidade” (INHELDER; BOVET; SINCLAIR, 1977; PIAGET; SZEMINSKA, 1975b); não de quantidade, o que exigiria dela reversibilidade - ainda parcial - de pensamento, característica 
do período operatório concreto; ela enfrenta dificuldades para dizer oito brinquedos, catorze laranjas, mas sabe que há muitos brinquedos ou um montão de laranjas, podendo enumerá-los. Só com a gênese da noção de número, possibilitada pela gênese da conservação da quantidade, ela consegue fazer pequenas somas e subtrações como operações reversíveis. Se é possível que uma criança chegue a isso com cinco anos, muitas delas só constroem essa noção mais tarde; e, em nosso meio social, muitas bem mais tarde, pois tal construção é tributária de processos complexos, "de integração entre a sequência dos numerais, a contagem e o seu significado" (FERREIRA, 2012, p. 203), que ela vem construindo pelo menos desde o final do período sensório-motor. Professores de Ensino Fundamental dão conta de que é frequente encontrar crianças de nove ou dez anos de idade que ainda não têm noção de número, o que impossibilita a aprendizagem de operações aritméticas elementares.

Como evoluem tais capacidades? Piaget (1973b, p. 50), ao falar da evolução das capacidades inteligentes ou dos estádios do desenvolvimento cognitivo, afirma que sua evolução "depende da experiência anterior dos indivíduos e não somente de sua maturação, e depende principalmente do meio social que pode acelerar ou retardar o aparecimento de um estádio, ou mesmo impedir sua manifestação". A partir do início das operações concretas, a criança constrói um sistema quantitativo por diferenciação de seu sistema lógico qualitativo que veio construindo desde seu nascimento. A construção da matemática torna-se possível a partir desse sistema. Como diz, com propriedade, uma professora universitária entrevistada: “Eu creio que por trás do conhecimento matemático sempre há uma estrutura lógica”.

E na história humana, quando surgiram as primeiras respostas matemáticas aos problemas enfrentados por grupos humanos? Se a Matemática como sistema mais organizado, racional, surgiu 200 anos a.C., podemos imaginar as dificuldades da criança para dar conta, em poucos anos, desses demorados processos cognitivos da humanidade.

O cérebro humano moderno está preparado para construir os instrumentos cognitivos para se habilitar a assimilar os conhecimentos matemáticos da humanidade. O sujeito não herda essas capacidades nem as obtém por maturação ou por pressão do meio social, por mais importantes que sejam esses dois fatores. Precisa construí-las. Do mesmo modo que a fala. Não importa quantas línguas falem seus pais, a criança tem que construir a capacidade simbólica e aprender a língua vernácula - atualmente se chama primeira língua -, com um repertório básico de palavras, a partir do zero.

Quase todos os docentes entrevistados entendem que essas capacidades são produzidas pelo ensino (empirismo) de pais ou professores. Alguns imaginam que os indivíduos as herdam geneticamente (inatismo) ou as têm a priori (apriorismo). Portanto, não a concebem como ação 
espontânea, que brota no indivíduo como necessidade, mas ação guiada pelo professor ou pelos pais. "Primeiro, se aprendem certos conceitos, mas, para poder realmente internalizá-los, tem que exercitar muitíssimo”. Só com muitas dificuldades e hesitações alguns docentes chegam a atribuir a emergência de capacidades matemáticas à ação do sujeito. Capacidades das quais os sujeitos tomam consciência e vão assumindo seu processo de desenvolvimento, mas sempre monitorados pelo ensino.

A pergunta sobre a origem do conhecimento matemático causa estranheza aos docentes e não poucos afirmam ou dão a entender que nunca pensaram nisso. Como se esse conhecimento sempre tivesse existido. Compreende-se, então, que as afirmações de que a Matemática está em tudo ou que sempre existiu, repetidas como mantras no ensino dessa disciplina, causam mais estragos do que se imagina à primeira vista. Se a Matemática sempre existiu, não é obra da humanidade e o professor não desafiará o aluno a construí-la; apenas transmitirá conteúdos para que o discente vá estocando. Se a Matemática não é uma construção humana, quem a construiu?

A matemática é uma construção humana. Como toda capacidade cognitiva, o sujeito a constrói partindo do mais simples ao mais complexo, de seus esquemas de ações sensóriomotoras às estruturas formais. Pensando a partir da teoria de Piaget (1973a), como aparece no seu livro Biologia e conhecimento, e de conquistas das neurociências, podemos afirmar que o cérebro do bebê humano vem "preparado" para se adaptar às características do mundo físico, produzindo um sistema lógico que não reflete apenas a organização deste mundo, mas, sobretudo, a organização de suas ações sobre o mundo. Para Einstein, segundo Isaacson (2007), "O fato de que o cosmos é compreensível, de que ele obedece a leis, é digno da mais profunda admiração" (p. 561) e "Convenci-me mais e mais de que a natureza poderia ser vista como uma estrutura matemática relativamente simples" (p. 37).

A pergunta seguinte é: como explicar a adequação da Matemática a esse mundo, se ela não é copiada da natureza, não resulta do ensino e, também, não é inata? A resposta está na plasticidade cerebral, conceito recente das neurociências, mas já amplamente presente (não com esse nome) n'O nascimento da inteligência na criança, obra de Piaget (1978a). O cérebro modifica-se na medida das ações do sujeito sobre o mundo; ele se organiza à medida das ações da criança sobre o mundo para compreendê-lo. Daí sua adequação.

Ao agir sobre o meio, a criança retira qualidades dos objetos e de suas próprias ações. Ao agir assim, ela pode retirar dos objetos características que os objetos não tinham antes de sua ação sobre eles; características que não são dos objetos, mas de suas ações. Ela faz isso ao classificar, seriar, enumerar, somar, subtrair, multiplicar, dividir etc. As classes e relações que ela atribui aos objetos não pertencem aos objetos, mas às suas ações. Ao dividir 30 laranjas para 
dez pessoas, a divisão não está nas laranjas; ela é característica da ação do sujeito. Quando o sujeito enumera uma série de objetos e atribui o quatro a um deles, o quatro não é uma característica do objeto, mas da ação do sujeito sobre o objeto; a tal ponto que ele poderá, em seguida, tirar o quatro daquele objeto e atribuí-lo a outro. Isso acontece com toda a matemática.

O mundo é o que é pelo Big Bang e por todos os processos que se seguiram a essa explosão primordial; jamais poderemos dizer que ele é matemático; mas, podemos afirmar, sim, que ele é matematizável. Matemático é o ser humano que estrutura matematicamente o mundo. Piaget (1995) chama essa ação do sujeito, de tirar dos objetos características ou relações que ele próprio colocou neles, de abstração pseudo-empírica (BECKER, 2014; 2017), que é uma modalidade da abstração reflexionante. Por essa abstração, o sujeito constrói todo tipo de novidade, retirando qualidades, não mais dos objetos, mas das coordenações de suas ações. Consegue, inclusive, construir o que nunca observou, pois as coordenações de suas ações não são observáveis; como diz um docente, “um círculo perfeito não existe na natureza”, mas o sujeito o constrói e nenhum matemático duvida desse conhecimento. A Matemática é uma das maravilhosas criações do sujeito humano. Se a Matemática está em tudo, como diz uma docente, na natureza, nas compras a crédito, na intensidade do terremoto, nos descontos à vista, nos juros a prazo, é porque o sujeito a colocou lá; não porque estava lá, previamente, desde sempre.

Além daquele que afirma que a matemática está em tudo, há dois mitos ou duas crenças a respeito do ensino, especialmente de matemática. O primeiro é de que é possível transmitir conceitos; o segundo, que se herda, geneticamente, predisposições ou até as capacidades matemáticas desenvolvidas pelos pais. Tais mitos só podem ser superados pela concepção construtivista das capacidades cognitivas.

A maior parte das manifestações dos docentes vai na direção contrária à da busca da fundamentação epistemológica; esta quase inexiste. Ela vai na direção da aplicabilidade do conhecimento matemático; inclusive entre pesquisadores de Matemática pura. Há quase geral ausência de preocupação com a fundamentação do conhecimento matemático - sua natureza, sua identidade, sua gênese; mas, uma intensa preocupação com sua aplicação - o que é importante, mas não suficiente. Simplificando a fala de uma professora universitária: “ $A$ matemática está na mente, mas as pessoas estão na vida real”. Por isso, as respostas dão a entender que é importante que se diga e se mostre para que serve a Matemática. De acordo com a prática desses docentes, o ensino não deve se preocupar com questões epistemológicas ou filosóficas, mas com a utilidade da Matemática na vida cotidiana.

Alguns docentes tomam consciência da provisoriedade da transmissão, de que ela está 
longe de ser condição suficiente de aprendizagem e, até, nem seja condição necessária, e começam a pensar na importância da ação do sujeito, do aluno. Vejamos suas manifestações: deve-se buscar "que ele [o aluno] racionalize, que vá tirando suas próprias conclusões dos distintos problemas e dos distintos exercícios" (P10); "pode-se transmitir noções, elaborar definições, mas a pessoa tem que encontrar caminhos" (P5); "há o momento de exercitar para fazer as conexões na cabeça e ver realmente do que se está falando" (P1); "é a pessoa que tem que dar o pulo. Tem que chegar uma hora de iluminação [...]” (P2); para transmitir conceitos, "tem que fazer com que o aluno experimente, pratique” (P12); “[...] o aluno precisa esforçarse; se não há esforço, não haverá aprendizagem” (P8); “[...] mas se o aluno não tentar algo com eles [os conceitos], por ele mesmo, não irá conseguir” (P13); “[...] nós vamos expor a parte conceitual, mas o aluno tem que trabalhar, tem que fazer” (P9); pode-se ajudar o aluno, fornecer estratégias, "[...] mas sua própria mente deve fazer conexões com a realidade do momento" (P14); "[...] o aprendiz vai desenvolvendo capacidade de abstração cada vez mais elevada e, então, [transforma] a manipulação física em manipulação mental, [...] em capacidade de manipular objetos matemáticos" (P15).

Não poucos docentes compreendem a importância da ação do aluno, mas não dispõem de uma teoria capaz de atribuir estatuto científico a essa compreensão. Talvez por isso continuem a transmitir conhecimentos e cobrar repetições, não conseguindo centralizar a atividade pedagógica na ação, na reflexão ou ação de segundo até enésimo grau, na experiência lógico-matemática ou nas coordenações das ações, na abstração reflexionante, especialmente a pseudo-empírica, na tomada de consciência do aluno que possibilita, finalmente, a formação de conceitos matemáticos.

Afinal, transmitem-se informações; capacidades cognitivas operatórias, como os conceitos, de modo todo especial os conceitos matemáticos, precisam ser construídas. É essa construção que produz conhecimento novo, que possibilita a passagem de conhecimentos ou capacidades cognitivas mais simples a conhecimentos ou capacidades cognitivas mais complexos. Conhecimentos novos, ou capacidades cognitivas, para o sujeito dessa construção, e, quem sabe um dia, conhecimento novo para a humanidade.

Os problemas epistemológicos mais fundamentais, subjacentes ao ensino de matemática (BECKER, 2013) dos docentes entrevistados, são similares - pode-se dizer quase idênticos aos encontrados no Brasil. São eles: predominância da concepção epistemológica empirista que contracena, aqui e ali, com a concepção apriorista, às vezes de caráter biologicamente inatista; a crença de que o conhecimento matemático pode ser transmitido do professor para o aluno, transmissão que explicaria o surgimento de conhecimentos matemáticos nos indivíduos; 
desconhecimento do processo de construção de capacidades cognitivas, processo responsável pela emergência das capacidades lógicas, depois, quantitativas; em síntese, de conhecimento novo. Diferenciam-se pela presença mais intensa de posições críticas que demandam pedagogia mais ativa e concebem a emergência das capacidades cognitivas matemáticas como resultantes da ação do sujeito. Ação que pode contar com contribuições substantivas da docência cujas ações jamais devem substituir a ação do sujeito da aprendizagem. Na continuidade da pesquisa saberemos se tais constatações se confirmam. Nossa hipótese é que sim.

\section{Referências}

BECKER, F. Educação e construção do conhecimento. 2 ed. Porto Alegre: Penso, 2012a.

BECKER, F. A epistemologia do professor de matemática. Petrópolis: Vozes, 2012b.

BECKER, F. Abstração pseudo-empírica e reflexionante: significado epistemológico e educacional. Schème - Revista Eletrônica de Psicologia e Epistemologia Genéticas, Marília v. 6, p. 103-127, 2014.

BECKER, F. Sujeito do conhecimento e ensino de matemática. Schème - Revista Eletrônica de Psicologia e Epistemologia Genéticas, Marília v. 5, p. 65-86, set. 2013.

BECKER, F. Abstração pseudo-empírica: significado epistemológico e impacto metodológico. Educação \& Realidade, Porto Alegre, v. 42, n. 1, p. 371-393, jan./mar. 2017.

BECKER, F. A epistemologia do professor: o cotidiano da escola. 16 ed., 2 reimpr. Petrópolis: Vozes, 2018.

DEVLIN, K. J. O instinto matemático: por que você é um gênio da matemática [assim como lagostas, pássaros, gatos e cachorros]? Rio de Janeiro: Record, 2009.

FREIRE, P. Conscientização: teoria e prática da libertação. São Paulo: Cortez \& Moraes, 1979. $\overline{\text { Terra, } 1997 .}$

Pedagogia da autonomia: saberes necessários à prática educativa. 3 ed. São Paulo: Ed. Paz e

FERREIRA, M. C. R. A construção do número: os modelos de Klahr \& Wallace; Von Glasersfeld e K. Fuson. Revista Semestral da Associação Brasileira de Psicologia Escolar e Educacional, São Paulo, v. 16, n. 2, p. 197-207, jul./dez. 2012.

INHELDER, B.; BOVET, M.; SINCLAIR, H. Aprendizagem e estruturas do conhecimento. São Paulo: Saraiva, 1977.

ISAACSON, W. Einstein: sua vida, seu universo. São Paulo: Companhia das letras, 2007.

KANT, E. Crítica da razão pura. 4. ed. Lisboa: Caloustre Gulbenkian, 1997.

MONTANGERO, J.; MAURICE-NAVILLE, D. Piaget ou a inteligência em evolução. Porto Alegre: Artmed, 1998.

PIAGET, J. O nascimento da inteligência na criança. 3 ed. Rio de Janeiro: Zahar, 1978a. 
; INHELDER, B. O desenvolvimento das quantidades físicas na criança; conservação e atomismo. 2. ed. Rio de Janeiro: Jorge Zahar, 1975a.

. A formação do símbolo na criança; imitação, jogo e sonho; imagem e representação. 3 ed. Rio de Janeiro: Zahar, 1978b.

. Biologia e conhecimento: ensaio sobre as relações entre as regulações orgânicas e os processos cognoscitivos. Petrópolis: Vozes, 1973a.

. Problemas de psicologia genética. Rio de Janeiro: Forense, 1973b.

. Desenvolvimento e aprendizagem. In: LAVATTELLY, C. S.; STENDLER, F. Reading in child behavior and development. New York: Hartcourt Brace Janovich, 1972.

A tomada de consciência. São Paulo: EDUSP/ Melhoramentos, 1977a.

Fazer e compreender. São Paulo: EDUSP/ Melhoramentos, 1977b.

. Abstração reflexionante: relações lógico-aritméticas e ordem das relações espaciais. Tradução de Fernando Becker e Petronilha B. G. da Silva. Porto Alegre: Artes Médicas, 1995.

; GRÉCO, P. Aprendizagem e conhecimento. Rio de Janeiro: Freitas Bastos, 1974.

et al. La enseñanza de las matemáticas. Madrid: Aguilar, 1968.

PIAGET, J.; SZEMINSKA, A. A gênese do número na criança. 2. ed. Rio de Janeiro: Zahar, 1975b.

PIAGET, J.; INHELDER, B. Gênese das estruturas lógicas elementares. 2. ed. Rio de Janeiro: Jorge Zahar, 1975c.

ROSSI, T. M. F.; ROSSI, F. F. O conceito de internalização em Vygotsky: algumas aproximações teóricas desde a semiótica peirceana. In: Colóquio Internacional "Educação e contemporaneidade", $6 .$. 2012, São Cristóvão. Anais... São Cristovão, 2012.

SZEMINSKA, A. Abstrações, diferenciações e integrações no emprego de operações aritméticas elementares. In: PIAGET, J. Abstração reflexionante: relações lógico-aritméticas e ordem das relações espaciais. Tradução de Fernando Becker e Petronilha B. G. da Silva. Porto Alegre: Artes Médicas, 1995. p. 9-29. 